\title{
Identification of Selenoprotein P Fragments as a Cell-Death Inhibitory Factor
}

\author{
Masaki Hirashima, ${ }^{a}$ Takeshi Naruse, ${ }^{a}$ Hiroaki Maeda,${ }^{a}$ Chikateru Nozaki,${ }^{a}$ Yoshiro SAito, ${ }^{b, c}$ and \\ Kazuhiko TAKAHASHI $*$,b \\ ${ }^{a}$ The Chemo-Sero-Therapeutic Research Institute; Kawabe, Kyokushi, Kikuchi-gun, Kumamoto 869-1298, Japan: \\ ${ }^{b}$ Department of Hygienic Chemistry, Graduate School of Pharmaceutical Sciences, Hokkaido University; Kita 12 Nishi 6 , \\ Kita-ku, Sapporo 060-0812, Japan: and ${ }^{c}$ Human Stress Signal Research Center, National Institute of Advanced Industrial \\ Science and Technology; 1-8-31 Midorigaoka, Ikeda, Osaka 563-8577, Japan. \\ Received February 5, 2003; accepted March 5, 2003, published online March 7, 2003
}

\begin{abstract}
Megakaryoblastoma (Dami cells) cultured in a serum-free medium containing albumin, proliferated for three days but died on the fourth day. This cell death was not observed when human plasma was added, suggesting that human plasma contains a cell-death inhibitory factor. In order to identify this factor, we purified it from human plasma. N-terminal amino acid sequence analysis revealed that this factor is a mixture of $\mathrm{C}$-terminal fragments of selenoprotein $P$, a major selenocysteine-containing protein in plasma. The specific activity (unit per pmol of selenium) of selenoprotein $P$ fragments protein was 15 -fold and 1900 -fold higher than that of the fulllength SeP and sodium selenite, respectively.
\end{abstract}

Key words selenoprotein P; serum-free culture; albumin; cell death; selenium

Albumin has been widely utilized as a medicine, a cellculture supplement and a protein stabilizer. Stable cell-proliferation is generally supported by the addition of albumin to the culture medium. ${ }^{1-3)}$ However, it has also been reported that cell damage is potentiated by the addition of albumin in vivo ${ }^{4-6)}$ and in vitro. ${ }^{7-9)} \mathrm{We}$ observed that commercially available human albumin (Fraction V) induced the death of megakaryoblastoma (Dami cells) under serum-free conditions and this cell death could be inhibited by the addition of plasma.

Selenoprotein $\mathrm{P}(\mathrm{SeP})$ is a selenium-rich extracellular glycoprotein ${ }^{10)}$ and human $\mathrm{SeP}$ has been purified and studied by several groups. ${ }^{11-13)}$ The sequence of the cDNA predicts that human SeP contains 10 selenocysteines encoded by UGA stop codons in the open reading frame of its mRNA. ${ }^{14)}$ The function of $\mathrm{SeP}$ in vivo is currently unknown, although several pieces of indirect evidence suggest that $\mathrm{SeP}$ is a free radical scavenger ${ }^{15,16)}$ or Se transporter. ${ }^{17)} \mathrm{SeP}$ has been reported to catalyze the reduction of phospholipid hydroperoxide by glutathione or thioredoxin, ${ }^{13,18)}$ function as a peroxynitrite scavenger, ${ }^{19)}$ and to be a cell survival-promoting factor in the primary culture of neurons. ${ }^{20)}$ Recently, we demonstrated that $\mathrm{SeP}$ supplies selenium to proliferating T lymphoma cells. ${ }^{21}$ ) In this paper, we identified the C-terminal fragments of SeP as a cell-death inhibitory factor in human plasma.

\section{MATERIALS AND METHODS}

Cell Culture and Cell-Death Inhibition Assay Dami cells $^{22}$ were maintained in a serum-free medium, SFO3 (Sanko Junyaku, Tokyo, Japan), at $37^{\circ} \mathrm{C}$ in a humidified atmosphere of $5 \% \mathrm{CO}_{2}$ and $95 \%$ air. In advance of the celldeath inhibition assay, $1 \mathrm{ml}$ of cell suspension $\left(1 \times 10^{6}\right.$ cells $/ \mathrm{ml}$ ) was added to $2 \mathrm{ml}$ of SA medium (SA: RPMI1640 medium/Dulbecco's modified Eagle's medium/Ham's F-12 medium, $1: 2: 2$ ), and the cells were cultured for three days. For the cell-death inhibition assay, the pre-cultured cells were cultured with an assay sample at $3 \times 10^{3}$ cells/well in an assay medium consisting of SA medium diluted with an equal volume of phosphate-buffered saline (pH 7.4, PBS) containing $0.1 \%$ human serum albumin (Fraction V, Sigma-Aldrich, Co., St. Louis, MO, U.S.A.). Four days later, the cell-death inhibitory activity was estimated by the quantitative colorimetric assay for cell survival, using cell-counting kit (Dojindo Laboratories, Kumamoto, Japan). The assay detects living, but not dead, cells and the signal generated is dependent on the degree of activation of the cells. The cell-death inhibitory activity (unit) was defined as the maximum dilution factor exhibiting complete inhibition of cell-death. The protein content was determined by CBB plus protein assay (Pierce Biotechnology, Rockford, IL, U.S.A.) with bovine serum albumin as a standard.

Purification of the Cell-Death Inhibitory Factor Step 1. Heparin-Sepharose Chromatography and Ammonium Sulfate Precipitation: Cryoprecipitate-removed human plasma (freshly prepared and frozen) was applied to a Heparin-Sepharose column (Amersham Biosciences Corp., Piscataway, NJ, U.S.A.) that was equilibrated with PBS. Proteins were eluted with $20 \mathrm{~mm}$ phosphate buffer ( $\mathrm{pH} 7.4)$ containing $2.0 \mathrm{M} \mathrm{NaCl}$ after the column was washed with $0.3 \mathrm{M} \mathrm{NaCl}$. The fraction eluted by $2.0 \mathrm{M} \mathrm{NaCl}$ was fractionated by the addition of ammonium sulfate at a final concentration of $2.0 \mathrm{M}$. The precipitate was collected after centrifugation, dialyzed against distilled water at $4{ }^{\circ} \mathrm{C}$ overnight, and the insoluble precipitate removed by filtration.

Step 2. Ion Exchange Chromatography: The supernatant obtained by step 1 was adjusted to $20 \mathrm{~mm}$ Tris- $\mathrm{HCl}$ (pH 8.0), and applied to a Macro-prep high Q column (Bio-Rad Laboratories, Hercules, CA, U.S.A.) equilibrated with $20 \mathrm{~mm}$ Tris- $\mathrm{HCl}(\mathrm{pH} \mathrm{8.0)}$. The cell-death inhibitory fraction was eluted with $20 \mathrm{~mm}$ Tris- $\mathrm{HCl}$ (pH 8.0) containing $40 \mathrm{~mm}$ $\mathrm{NaCl}$. The active fraction was adjusted to $\mathrm{pH} 4.0$ with $20 \mathrm{~mm}$ citrate and applied to a Macro-prep high S column (Bio-Rad Laboratories) equilibrated with $20 \mathrm{~mm}$ citrate buffer ( $\mathrm{pH} 4.0)$. The column was washed with $20 \mathrm{~mm}$ citrate buffer ( $\mathrm{pH} 4.0$ ) containing $0.22 \mathrm{M} \mathrm{NaCl}$, and the fraction was eluted with 
$0.55 \mathrm{M} \mathrm{NaCl}$.

Step 3. Hydrophobic Chromatography: The pooled active fractions obtained in step 2 were adjusted to $\mathrm{pH} 7.5$ by the addition of $1.0 \mathrm{M}$ Tris, and then adjusted to $1.4 \mathrm{M}$ ammonium sulfate by the addition of $20 \mathrm{~mm}$ Tris- $\mathrm{HCl}(\mathrm{pH} 7.5)$ containing $3.5 \mathrm{M}$ ammonium sulfate. The fractions were applied to a Macro-prep Methyl column (Bio-Rad Laboratories) equilibrated with $20 \mathrm{~mm}$ Tris $-\mathrm{HCl}(\mathrm{pH} 7.5)$ containing $0.33 \mathrm{M} \mathrm{NaCl}$ and $1.4 \mathrm{M}$ ammonium sulfate. Activity was recovered in a pass-through fraction. The active fractions were adjusted to $1.95 \mathrm{M}$ ammonium sulfate by the addition of $20 \mathrm{~mm}$ Tris- $\mathrm{HCl}$ ( $\mathrm{pH} 7.5$ ) containing $3.5 \mathrm{M}$ ammonium sulfate, and applied to a Macro-prep Methyl column equilibrated with $20 \mathrm{~mm}$ Tris- $\mathrm{HCl}(\mathrm{pH} 7.5)$ containing $0.24 \mathrm{M} \mathrm{NaCl}$ and $1.95 \mathrm{M}$ ammonium sulfate. The fraction was eluted with $20 \mathrm{~mm}$ Tris- $\mathrm{HCl}$ (pH 7.5). The active fractions were pooled, dialyzed against distilled water, and adjusted to $\mathrm{pH} 5.0$ by $1.0 \mathrm{M}$ citrate buffer ( $\mathrm{pH} 4.5$ ).

Step 4. Hi-Trap Heparin Chromatography: The fractions obtained by step 3 were applied to a Hi-trap Heparin column (Amersham Biosciences Corp.) that was equilibrated with $20 \mathrm{~mm}$ phosphate ( $\mathrm{pH}$ 6.5). Proteins were eluted with a linear $\mathrm{NaCl}$ gradient $(0-0.6 \mathrm{M})$. Active fractions, which were eluted with $0.15-0.2 \mathrm{M} \mathrm{NaCl}$, were pooled, and concentrated using Centricon YM-3 (Millipore, Bedford, MA, U.S.A.).

Step 5. Gel Filtration Chromatography: The concentrate obtained in step 4 was fractionated using a Superdex $200 \mathrm{pg}$ column (Amersham Biosciences Corp.) equilibrated with 2\% acetic acid and $0.5 \mathrm{M} \mathrm{NaCl}$. The active fractions were then pooled.

Step 6. Reverse-Phase Chromatography: The pooled fractions were applied to 214TP54 (Grace Vydac, Hesperia, CA, U.S.A.) that was equilibrated with $1 \%$ acetonitrile containing $1 \%$ isopropanol and $0.1 \%$ trifluoroacetic acid. Proteins were eluted with a linear acetonitrile gradient $(1-40 \%)$ containing $1 \%$ isopropanol and $0.1 \%$ trifluoroacetic acid. Each of the eluted fractions was lyophilized and dissolved in $20 \mathrm{~mm}$ ethanolamine- $\mathrm{HCl}(\mathrm{pH} 9.15)$, and the active fractions were pooled.

Step 7. Mini Q Chromatography: The pooled fractions were applied to a Mini Q column (Amersham Biosciences Corp.) equilibrated with $20 \mathrm{~mm}$ ethanolamine- $\mathrm{HCl}$ (pH 9.15). Proteins were eluted with a linear $\mathrm{NaCl}$ gradient $(0-0.3 \mathrm{M})$. Finally, each of the active fractions, with two separated peaks exhibiting cell-death inhibitory activity, was collected, and dialyzed against PBS.

Step 8. Monoclonal Antibody-Immobilized Column Chromatography: Mouse monoclonal antibody (MoAb) was prepared according to Kohler's method ${ }^{23}$ after immunization of the protein obtained in step 6 . MoAb, which is reactive to the active protein pooled in step 7, was purified from hybridoma culture supernatants using protein-A affinity chromatography. One mg of the MoAb was conjugated with $1 \mathrm{ml}$ of NHSactivated Sepharose (Amersham Biosciences Corp.). The pooled active fractions obtained by step 7 were applied to the MoAb-immobilized column equilibrated with PBS, and eluted with $20 \mathrm{~mm}$ citrate buffer ( $\mathrm{pH} 4.0$ ) containing $4 \mathrm{~m}$ urea. The eluted fractions were collected and dialyzed against PBS.

Electrophoresis, Selenium Quantification, and Amino Acid Sequence Analysis Sodium dodecyl sulfate-poly- acrylamide gel electrophasis (SDS-PAGE) was performed according to Laemmli's method. ${ }^{24)}$ The protein bands were stained using a silver staining kit (Kanto Chemical Co., Tokyo, Japan). Selenium content was quantified by AAnalyst 600 atomic absorption spectrophotometer (Perkin Elmer, Wellesley, MA, U.S.A.). Amino acid sequence analysis of blots after SDS-PAGE was performed with an Applied Biosystems 492 protein sequencer (Applied Biosystems, Inc., Tokyo, Japan).

Assay of the Cell-Death Inhibition Activity of Various Compounds The cell-death inhibition effect of seleniumcontaining compounds and proteins (sodium selenite, selenoL-methionine, seleno-DL-cystine, SeP, and SeP fragments) and anti-oxidative agents (glutathione, vitamin $\mathrm{C}$ and vitamin E) was assayed using the method described in Cell Culture and Cell-Death Inhibition Assay section. All compounds except SeP and SeP-fragments were purchased from SigmaAldrich, Co. Full-length SeP was purified according to the method of Saito et al. ${ }^{13)}$

Detection of Intracellular Hydroperoxide Production 5-(and-6)-Carboxy-2' ,7'-dichlorodihydrofluorescein diacetate (carboxy- $\mathrm{H}_{2} \mathrm{DCFDA}$; Molecular Probes, Eugene, OR, U.S.A.) was used to detect the oxidative status of the cells. ${ }^{25)}$ The pre-cultured cells were cultured at $2.5 \times 10^{5}$ cells/well with or without SeP fragments $(0.8 \mu \mathrm{g} / \mathrm{ml})$ for $18 \mathrm{~h}$ in an assay medium consisting of SA medium containing $0.1 \%$ human serum albumin (Fraction V) or fatty acid-free human serum albumin (Sigma-Aldrich, Co., St. Louis, MO, U.S.A.). After $2 \mathrm{~h}$ of further incubation with carboxy-H ${ }_{2}$ DCFDA $(500 \mathrm{nM})$, the cells were washed twice and analyzed by using a FACScan flow cytometer (Becton Dickinson Immunocytometry Systems, Inc., Mountain View, CA, U.S.A.).

Glutathione Peroxidase (GPx) Enzyme Assay GPx activities were examined by following the oxidation of NADPH in the presence of GSH reductase, which catalyzes the reduction of the oxidized GSH formed by GPx. ${ }^{13)}$

\section{RESULTS AND DISCUSSION}

Megakaryoblastoma (Dami) cells proliferate normally under serum-free culture conditions in the absence of albumin (Fig. 1). When cultured with a serum-free medium containing human albumin (Fraction V), the cells proliferated normally until the third day, but all cells died by the fourth day. However, this cell-death was completely inhibited by the addition of a 1/1000 volume of human plasma. Morphological observation and DNA fragmentation analysis suggest that

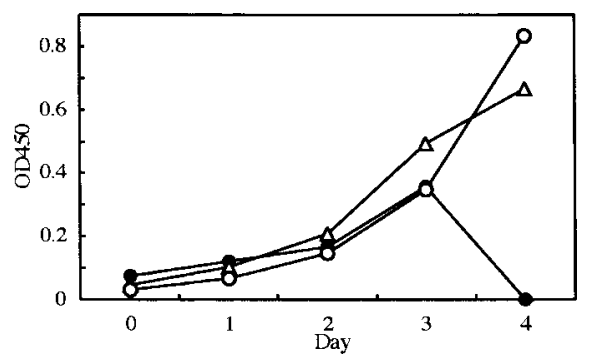

Fig. 1. Effects of Albumin and Plasma on Dami Cell Growth under Serum-Free Conditions

The growth curves of the Dami cells; triangle: albumin $(-)$, plasma $(-)$; closed circle: albumin $(+)$, plasma $(-)$; open circle: albumin $(+)$, plasma $(+)$. The quantification of cells was determined using a cell-counting kit. 
Table 1. Purification of a Cell-Death Inhibitory Factor from 3001 of Human Plasma

\begin{tabular}{|c|c|c|c|c|}
\hline & $\begin{array}{l}\text { Total protein }{ }^{a)} \\
\text { (mg) }\end{array}$ & $\begin{array}{c}\text { Total activity }{ }^{b)} \\
\quad \text { (units) }\end{array}$ & $\begin{array}{l}\text { Purification } \\
\quad \text { (-fold) }\end{array}$ & $\begin{array}{l}\text { Yield } \\
(\%)\end{array}$ \\
\hline Plasma & 18000000 & 450000000 & (1) & $(100.00)$ \\
\hline Heparin-Sepharose $e^{c)}$ & 22000 & 12760000 & 23 & 2.84 \\
\hline Macroprep HQ & 2100 & 6300000 & 120 & 1.40 \\
\hline Macroprep HS & 448 & 2016000 & 180 & 0.45 \\
\hline Macro-prep Methyl & 40 & 1280000 & 1280 & 0.28 \\
\hline Hi-trap Heparin & 28 & 1148000 & 1640 & 0.26 \\
\hline Superdex $200 \mathrm{pg}$ & 3.4 & 435200 & 5120 & 0.10 \\
\hline $214 \mathrm{TP} 54$ & 1.8 & 396000 & 9000 & 0.09 \\
\hline MoAb-Sepharose & 0.48 & 384000 & 32000 & 0.09 \\
\hline
\end{tabular}

a) The protein content was determined by CBB plus protein assay with bovine serum albumin as a standard. b) The cell-death inhibitory activity (unit) was defined as the maximum dilution factor exhibiting complete inhibition of cell-death. c) The precipitate of $2 \mathrm{~m} \mathrm{NaCl}$ eluate from heparin-Sepharose by $2 \mathrm{~m}$ ammonium-sulfate.

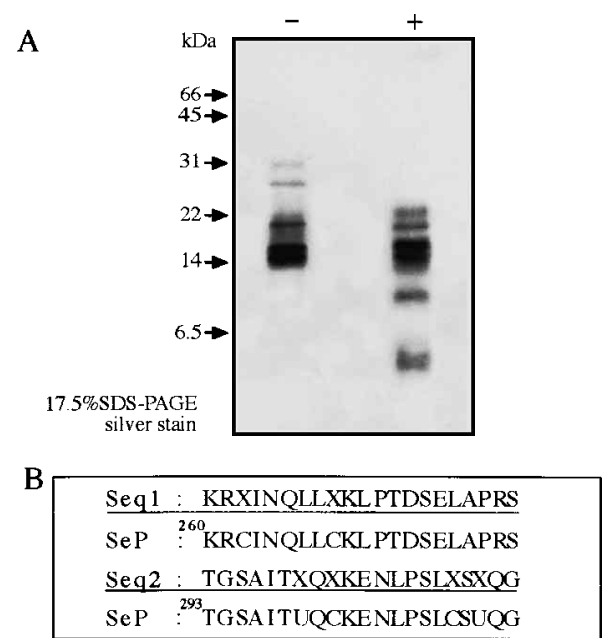

Fig. 2. Analysis of the Purified Factor by SDS-PAGE and Amino Acid Sequence Analysis

(A) SDS-PAGE of the purified factor non-reduced $(-)$ or reduced $(+)$ with 2-mercaptoethanol. (B) Seq1 and Seq2 show N-terminal sequences of each band of the purified factor. $X$ indicates undetected. SeP shows the sequences starting from the 260th and 293rd amino acid of SeP. ${ }^{14)} \mathrm{U}$ represents a selenocysteine residue.

this cell-death is caused by the lysis of the cell membrane rather than by apoptosis (data not shown). Essentially the same results were obtained using monocytic leukemia (THP1), histiocytic lymphoma (U937), myelomonocytic leukemia (HL-60), epitheloid carcinoma (HeLa), lymphoblastic leukemia (Molt-4) and teratocarcinoma (NT2) cells, suggesting that cell-death inhibition by plasma is a general phenomenon.

To identify the cell-death inhibitory factor, we performed the purification procedure shown in Materials and Methods. After MoAb-immobilized column chromatography, final active fractions ( 800000 units/mg of protein) were obtained (Table 1). The SDS-PAGE patterns are shown in Fig. 2A. Under non-reduced conditions, two major bands $(14,16 \mathrm{kDa})$ and three minor bands $(19,25,29 \mathrm{kDa})$ were observed. Under reduced conditions, two major bands $(14,16 \mathrm{kDa})$ and four minor bands $(4,10,18,22 \mathrm{kDa})$ were observed. Subsequently, the N-terminal sequence of each protein after SDSPAGE blotting was determined (Fig. 2B). 4-, 18- and 22-kDa bands on SDS-PAGE showed an amino acid sequence corresponding to the sequence starting with the 260th lysine of $\mathrm{SeP}^{14)}$ (Fig. 2B, Seq1). The 10-kDa band showed another sequence starting at the 293rd threonine of SeP (Fig. 2B,
Table 2. Effects of Selenium-Containing Compounds and Anti-oxidants on the Cell-Death of Dami Cells

\begin{tabular}{lc}
\hline \hline & $\begin{array}{c}\text { Specific activity } \\
\text { (units/pmol of selenium or compounds) }\end{array}$ \\
\hline Sodium selenite & 1.0 \\
Seleno-L-methionine & 0.4 \\
Seleno-DL-cystine & 67 \\
Selenoprotein P (full length) & 130 \\
Selenoprotein P (fragments) & 1910 \\
Vitamin E & 5.2 \\
Vitamin C & 0 \\
Glutathione (reduced) & 0
\end{tabular}

The pre-cultured cells were cultured in an assay medium consisting of SA medium diluted with an equal volume of PBS containing $0.1 \%$ human serum albumin. Four days later, the cell-death inhibitory activity was estimated by cell-counting kit. The celldeath inhibitory activity (unit) was defined as the maximum dilution factor exhibiting complete inhibition of cell-death. Selenium content was quantified by atomic absorption spectrophotometer.

Seq2). The heterogeneous patterns of SDS-PAGE suggests that the obtained fractions contain the SeP fragments in a nicked form, a dimerized form and a heterogeneously glycosylated form. Although various sizes of protein exist in the active fractions, we confirmed that all of them consist of the same region of SeP. This result suggests that the structure essential for cell-death inhibitory activity is derived from the sequence following the 260th lysine of SeP. We assume that our purified SeP fragments possibly consist of 103 amino acids up to the C-terminal end (the 362nd asparagine) because the molecular sizes of the bands on SDS-PAGE under non-reduced conditions were found to be over $14 \mathrm{kDa}$. Only one selenocysteine residue is located in the N-terminal region of SeP, while the remaining 9 selenocysteine residues are predicted to be located in the C-terminal third. ${ }^{14)} 640$ nmoles of selenium per mg of protein were found in this $\mathrm{C}$ terminal fragments.

In order to examine whether the cell-death inhibitory activity of the SeP fragments was due to the anti-oxidative effect of selenium, we compared the inhibitory activities of selenium-containing compounds/proteins and various anti-oxidants. Three selenium-containing compounds and the fulllength SeP also showed cell-death inhibitory activities (Table 2). SeP fragments showed the highest cell-death inhibitory activity. The specific activity (unit per pmol of selenium) of SeP fragments protein was 15 -fold and 1900 -fold higher than that of the full-length SeP and sodium selenite, respectively. Vitamin E also shows cell-death inhibition (5.2 units per pmol), although glutathione and vitamin $\mathrm{C}$ shows no inhibi- 

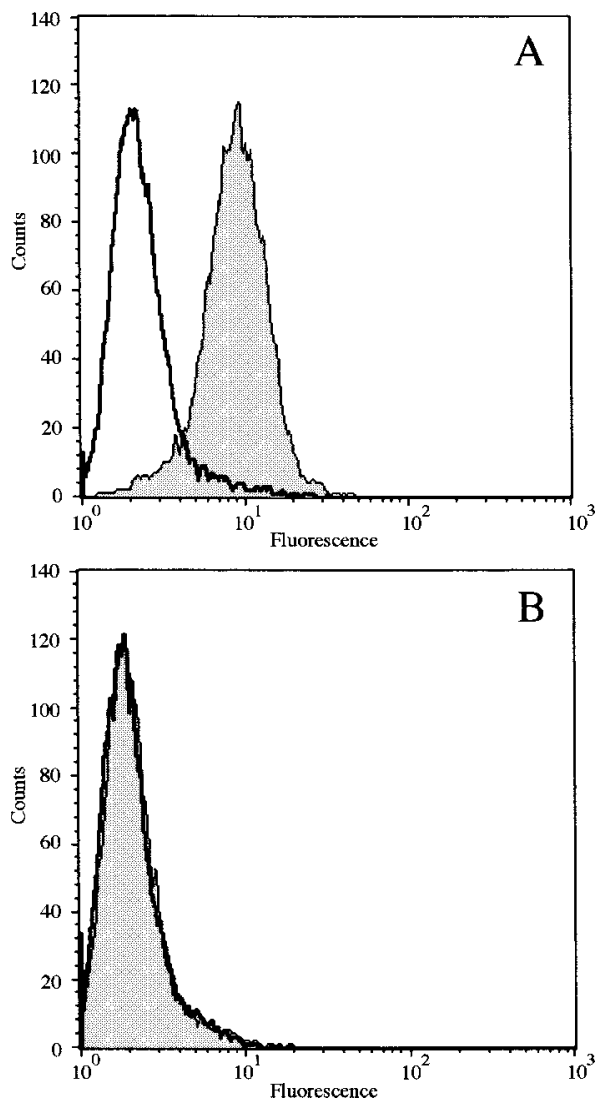

Fig. 3. Analysis of Hydroperoxide Production in Dami Cells

Dami cells were labeled with the fluorescent dye and then analyzed by flow cytometry. (A) The cells were cultured with (solid line) or without (shaded) SeP fragments $(0.8 \mu \mathrm{g} / \mathrm{ml})$ in an assay medium containing human serum albumin (Fraction V). (B) The cells were cultured with (solid line) or without (shaded) SeP fragments $(0.8 \mu \mathrm{g} / \mathrm{ml})$ in an assay medium containing fatty acid-free human serum albumin.

tion. This finding suggests that cell-death inhibition activity might depend on anti-oxidative activity against water-insoluble oxidant such as lipid hydroperoxide. As we recently demonstrated that full-length SeP supplies selenium to proliferating $\mathrm{T}$ lymphoma cells ${ }^{21)}$ and the $\mathrm{C}$-terminal fragments of SeP did not exhibit any phospholipid hydroperoxide reducing activity (Saito Y. unpublished observation), we suppose that the SeP fragments supplies selenium to the cells and increases intracellular selenium-dependent anti-oxidant enzyme (such as glutathione peroxidase, phospholipid hydroperoxide glutathione peroxidase and thioredoxin reductase) activities. Other studies have shown that selenium supplements of a variety of cell types can prevent cell death following treatment with hydroperoxides. ${ }^{26-28)}$ In our preliminary experiments, commercially available fatty acid-free albumin could not induce cell-death. These facts suggest that one of the molecules inducing cell death may be a fatty acid or possibly its hydroperoxide derivative.

Next, we determined the intracellular hydroperoxide production in the cells using the oxidation-sensitive probe and flow cytometry. Figure 3A shows that the increase in fluorescence intensity caused by albumin is suppressed by SeP fragments as is the albumin-induced cell death. This strongly suggests the involvement of intracellular hydroperoxide production. Fatty acid-free albumin did not induce hydroperoxide production (Fig. 3B). Furthermore, no hydroperoxide production was observed in the absence of albumin (data not

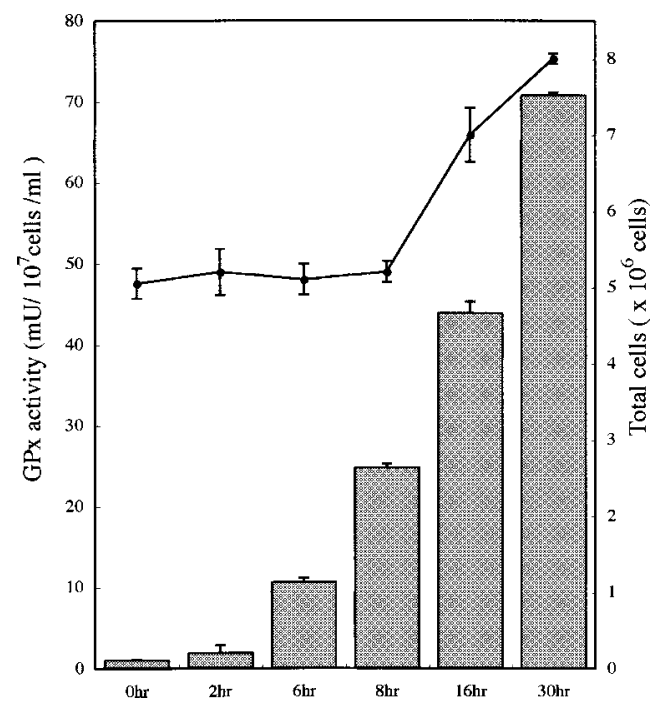

Fig. 4. Effect of SeP Fragments on the cGPx Activity of Dami Cells

The cells were cultured in the presence of $0.5 \mu \mathrm{g} / \mathrm{ml}$ purified SeP fragments in SA medium. The cell number (closed circle) and GPx activity (bar) was determined by the methods describe in Materials and Methods.

shown). These results support the hypothesis that a fatty acid hydroperoxide induces an increase in intracellular hydroperoxide production, which causes oxidative stress and cell death.

Finally, the effect of SeP fragments on cellular GPx activity was investigated (Fig. 4). The addition of purified SeP fragments $(0.5 \mu \mathrm{g} / \mathrm{ml})$ resulted in a time-dependent increase of GPx activity. We confirmed that the SeP fragments supplies selenium to the cells and increases intracellular selenium-dependent anti-oxidant enzyme.

As we did not add protease inhibitor (diisopropylfluorophosphate) during the purification, proteolysis of $\mathrm{SeP}$ occurred $^{13)}$ and a fraction with a much higher level of activity could be recovered. We currently do not know if proteolysis of SeP occurs in vivo. In our preliminary experiments, arachidonic acid and linoleic acid, which could be bound to albumin in vivo, induced cell death under our serum-free culture conditions, and the addition of SeP fragments could inhibit this cell death. It has been reported that fatty acids such as arachidonic acid are associated with inflammation and cell damage, ${ }^{29-31)}$ that proteases are activated at inflammatory sites, ${ }^{32-34)}$ and that selenium modulates the inflammatory and immune responses. ${ }^{35,36)}$ Therefore, it is possible that protease-processed SeP fragments regulate inflammation by controlling selenium action in the cells. Through an examination of this point, we intend to clarify the in vivo functions of SeP and its fragment.

Whereas the SeP fragment showed no cytotoxicity at $9 \mu \mathrm{g} / \mathrm{ml}$ of selenium, sodium selenite and selenocystine showed cytotoxicity at $30 \mathrm{ng} / \mathrm{ml}$ and $160 \mathrm{ng} / \mathrm{ml}$ of selenium, respectively (data not shown). This suggests that the selenium in the SeP fragments act more effectively on cell-death inhibition without cytotoxicity than do other selenium compounds. Moreover, the SeP fragments have a higher specific activity than does the full-length SeP. The SeP fragments might have a specialized structure for supplying selenium to cells without cytotoxicity. As selenium is covalently bound in $\mathrm{SeP}$ and its fragments, the supply mechanism is supposed to 
require digestion of $\mathrm{SeP}$ and its fragments by proteases and peptidases, and the breakdown of selenocysteine for release of its selenium. Further studies to clarify this mechanism are necessary in the future.

Acknowledgements We would like to thank Hatsui Sunagawa and Akiyo Matsumi for their technical assistance, and Tim Corrigan and Kenji Soejima for their critical reading of the manuscript.

\section{REFERENCES}

1) Polet H., Spieker-Polet H., J. Exp. Med., 142, 949—959 (1975).

2) Yamane I., Murakami O., Kato M., Proc. Soc. Exp. Biol. Med., 149, 439-442 (1975)

3) Hoshi H., Kan M., Yamane I., Ohno T., Namba M., Cell Struct. Funct., 8, 67-75 (1983).

4) Hassel B., Iversen E. G., Fonnum F., Neurosci. Lett., 167, 29-32 (1994).

5) Schreiner G. F., Curr. Opin. Nephrol. Hypertens., 4, 369-373 (1995).

6) Brunskill N. J., Cockcroft N., Nahorski S., Walls J., Am. J. Physiol., 271, F356-364 (1996).

7) Yamada M., Okigaki T., Awai M., Cell Biol. Int. Rep., 11, 707-716 (1987).

8) Eimerl S., Schramm M., Neurosci. Lett., 130, 125-127 (1991).

9) Si Q. S., Nakamura Y., Kataoka K., Glia, 21, $413-418$ (1997).

10) Saito Y., Takahashi K., J. Health. Sci., 46, 409-413 (2000).

11) Mostert V., Lombeck I., Abel J., Arch. Biochem. Biophys., 357, 326330 (1998).

12) Akesson B., Bellew T., Burk R. F., Biochim. Biophys. Acta, 1204, 243-249 (1994).

13) Saito Y., Hayashi T., Tanaka A., Watanabe Y., Suzuki M., Saito E., Takahashi K., J. Biol. Chem., 274, 2866-2871 (1999).

14) Hill K. E., Lloyd R. S., Burk R. F., Proc. Natl. Acad. Sci. U.S.A., 90, 537-541 (1993).

15) Burk R. F., Hill K. E., Awad J. A., Morrow J. D., Kato T., Cockell K. A., Lyons P. R., Hepatology, 21, 561—569 (1995).
16) Atkinson J. B., Hill K. E., Burk R. F., Lab. Invest., 81, 193-200 (2001).

17) Motsenbocker M. A., Tappel A. L., Biochim. Biophys. Acta, 719, $147-153$ (1982).

18) Takebe G., Yarimizu J., Saito Y., Hayashi T., Nakamura H., Yodoi J., Nagasawa S., Takahashi K., J. Biol. Chem., 277, 41254-41258 (2002).

19) Arteel G. E., Mostert V., Oubrahim H., Briviba K., Abel J., Sies H., Biol. Chem., 379, 1201-1205 (1998).

20) Yan J., Barrett J. N., J. Neurosci., 18, 8682-8691 (1998).

21) Saito Y., Takahashi K., Eur. J. Biochem., 269, 5746-5751 (2002).

22) Greenberg S. M., Rosenthal D. S., Greeley T. A., Tantravahi R., Handin R. I., Blood, 72, 1968-1977 (1988).

23) Kohler G., Milstein C., Nature (London), 256, 495- 497 (1975).

24) Laemmli U. K., Nature (London), 227, 680 - 685 (1970).

25) Lee Y. J., Galoforo S. S., Berns C. M., Chen J. C., Davis B. H., Sim J. E., Corry P. M., Spitz D. R., J. Biol. Chem., 273, 5294-5299 (1998).

26) Hornsby P. J., Pearson D. W., Autor A. P., Aldern K. A., Harris S. E., J. Cell Physiol., 123, 33-38 (1985).

27) Miller S., Walker S. W., Arthur J. R., Nicol F., Pickard K., Lewin M. H., Howie A. F., Beckett G. J., Clin. Sci. (London), 100, 543-550 (2001).

28) Leist M., Maurer S., Schultz M., Elsner A., Gawlik D., Brigelius-Flohe R., Biol. Trace. Elem. Res., 68, 159-174 (1999).

29) Davies P., Bailey P. J., Goldenberg M. M., Ford-Hutchinson A. W., Annu. Rev. Immunol., 2, 335-357 (1984).

30) Wenzel S. E., Pharmacotherapy, 17, 3S-12S (1997).

31) Trimborn M., Iwig M., Glanz D., Gruner M., Glaesser D., Ophthalmic. Res., 32, 87-93 (2000).

32) Esmon C. T., Fukudome K., Mather T., Bode W., Regan L. M., Stearns-Kurosawa D. J., Kurosawa S., Haematologica, 84, 254-259 (1999).

33) Neumar R. W., Ann. Emerg. Med., 36, 483-506 (2000).

34) Cirino G., Bucci M., Cicala C., Napoli C., Trends Pharmacol. Sci., 21, $170-172$ (2000).

35) Peretz A. M., Neve J. D., Famaey J. P., Semin Arthritis Rheum, 20, 305-316 (1991).

36) Altimira J., Prats N., Lopez S., Domingo M., Briones V., Dominguez L., Marco A., J. Comp. Pathol., 123, 104-109 (2000). 